\title{
Ceramic Water Filters: A Point-of-Use Water Treatment Technology to Remove Bacteria from Drinking Water in Longhai City, Fujian Province, China
}

\author{
C. Farrow ${ }^{1}$, E. McBean ${ }^{1,3}$, G. Huang 2 , A. L. Yang ${ }^{3}$, Y. C. Wu' Z. Liu $^{3}$, Z. N. Dai ${ }^{3}$, \\ H. Y. Fu ${ }^{3}$, T. Cawte ${ }^{1}$, and Y. P. $\mathrm{Li}^{3}$ \\ ${ }^{1}$ School of Engineering, University of Guelph, Guelph N1G 2W1, Canada \\ ${ }^{2}$ Faculty of Engineering and Applied Science, University of Regina, Regina S4S 0A2, Canada \\ ${ }^{3}$ School of Environmental Science and Engineering, Xiamen University of Technology, Xiamen 361024, China
}

Received 29 September 2016; revised 4 December 2017; accepted 12 February 2018; published online 10 June 2018

\begin{abstract}
While provision of safe drinking water is considered a basic human right, there are major challenges in the developing world for its provision. The ability to deliver safe water using a cost-appropriate technology is a major aspect of the problem. One of the technologies that has the potential to contribute significantly is the ceramic water filter (CWF); however, as shown herein, there are significant differences between performance of CWFs in the laboratory and in field applications. The CWFs employed in this study (field and laboratory) have a pore fraction of $21.0-22.4 \%$ and an average maximum pore diameter of $5.7-15.2 \mu \mathrm{m}$. Field studies were completed in Longhai City, China, a rural community in southeastern China with red earth, high precipitation and intensive human/ domestic activities. During field trials, CWFs demonstrated an average removal efficiency of $94.7 \%$, with values ranging from 75 $100 \%$, whereas in laboratory studies, average removal efficiency was determined to be $99.5 \%$, with values ranging from $97.7-99.9 \%$. Differences between the lab and field removal efficiencies are attributed to contamination of the filter element and receptacle by villagers during field utilization and cleaning. Effective technology transfer to the end-user is required to achieve the bacterial removal efficiency attainable by the technology itself.
\end{abstract}

Keywords: ceramic water filter (CWF), drinking water treatment, point-of-use (POU) water treatment, technology transfer

\section{Introduction}

The World Health Organization defines access to safe drinking water as a basic human right. As of 2015, 663 million people (approximately $1 / 10^{\text {th }}$ of the global population) lacked access to a safe drinking water supply and 2.4 billion people $\left(1 / 3^{\text {rd }}\right.$ of the global population) lacked access to adequate sanitation (WHO/UNICEF, 2015). Inadequate sanitation facilities are a major cause of disease worldwide (WHO, 2017) due to faecal contamination of drinking water sources. There is a clear need for improved safe water provision and basic sanitation, but identification of approaches that will function consistently, including methodologies/ technologies to minimize faecal contamination of drinking water, remains a major obstacle to the provision of potable water (WHO/UNICEF, 2015; WHO, 2017) and much work remains to provide universal access to safe drinking water supplies.

The shortfall in provision of safe drinking water is particularly significant due to the impact of faecal contamination

\footnotetext{
${ }^{*}$ Corresponding author. Tel.: + 5198377612.

E-mail address: cfarrow@uoguelph.ca (C. Farrow).
}

ISSN: $1726-2135$ print/1684-8799 online

(C) 2018 ISEIS All rights reserved. doi:10.3808/jei.201800388 on human health. Diarrhoeal diseases, caused primarily by microbial contamination of drinking water, are the second leading cause of death in children under five years of age (WHO, 2013). The global impact of diarrhoeal diseases is substantial: each year, there are 1.7 billion cases and 760,000 child fatalities (WHO, 2013). Fatalities due to diarrhoeal diseases are typically the result of severe dehydration and fluid loss, with malnourished children and immune-compromised individuals being at the highest risk (WHO/ UNICEF, 2015).

Although implementation of improved drinking water sources (e.g., piped water into dwellings, public taps, tubewells) represent desirable, long-term elements to provide safe drinking water, the installation and maintenance of these systems, particularly in rural areas, is difficult and economically impractical in many cases. Additionally, water is often contaminated during transport from centralized water sources (e.g., public taps) (Wright et al., 2004).

In response, promising solutions to supply safe drinking water to the rural poor are point-of-use (POU) water filtration devices, an example of which is the Ceramic Water Filter (CWF) (e.g., Murphy et al., 2010a, b; Farrow et al., 2014; Mellor et al., 2014; Berg, 2015). Additional POU technologies also exist (e.g., membrane filters, biosand filters, and candle filters) (Murphy et al. 2010c; Perez-Vidal et al., 2016). An economic assessment indicated that the cost of providing functional CWFs 
to a typical household for ten years is $\$ 63$ (assuming a functional life of 3.5 years); in contrast, the cost of providing a centralized water system for the same time period is approximately \$221/household (Ren et al., 2013). Hence, CWFs present a more affordable solution in comparison to conventional centralized systems.

CWFs are typically constructed of clay and milled rice husk. The mixture is separated into $7 \sim 8 \mathrm{~kg}$ balls and pressed into cylindrical pot form $(24 \times 34 \mathrm{~cm})$ (height $\times$ diameter). The CWFs are then fired at $830{ }^{\circ} \mathrm{C}$ to burn out the rice husk and provide a product with a controlled porosity, thus allowing adequate transmittance of water $(1 \sim 3 \mathrm{~L} / \mathrm{h})$. Lantagne (2001) reported pore diameters ranging from 0.6 to $3 \mu \mathrm{m}$ while van Halem (2006) reported a pore size distribution ranging from $0.02 \sim 200 \mu \mathrm{m}$, with a predominant pore size of $14 \mu \mathrm{m}$. After firing, the CWFs are placed in plastic receptacles to allow collection of filtered water as depicted in Figure 1.

Bacteria generally range in length from $1 \sim 50 \mu \mathrm{m}$; however, rod-shaped bacteria (including E. coli) are $0.3 \sim 1.5 \mu \mathrm{m}$ in diameter and $1 \sim 10 \mu \mathrm{m}$ in length (Tchobanoglous et al., 2003). Therefore, the considerable majority of $E$. coli are expected to be filtered from the influent during CWF operation.

In addition to filtration, the development of a biofilm on the surface of the CWF aids in the removal of pathogens. Silver nitrate and/or silver nanoparticles are also utilized as disinfectants in some cases (Oyanedel-Craver and Smith, 2008; Vinka, et al., 2008; Yakub and Soboyejo, 2012; Rayner et al., 2013). Hence, the combination of filtration, disinfection and biofilm development result in significant removal of microorganisms from source water during CWF operation.

Of interest is the degree of effectiveness of removal of waterborne pathogens. As described below, reported efficiencies within the technical literature vary, depending upon the conditions under which removal effectiveness was determined. Laboratory studies of the efficacy of E. coli reduction by CWFs have indicated log-phase reductions ranging from $2.4 \sim 7.0$

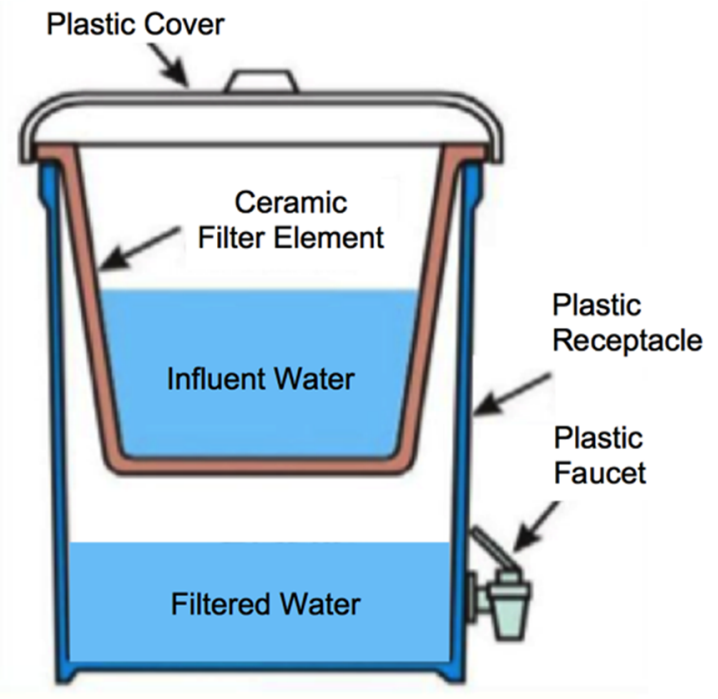

Figure 1. Ceramic water filter schematic.
(Lantagne, 2001; Fahlin, 2003; Campbell, 2005; Duke, 2006; van Halem, 2007; Thomas et al., 2015). Alternatively, field studies have indicated a broader range of results. An investigation by Malapane and Hackett (2012) in field tests in Limpopo Province, South Africa indicated E. coli removal efficiencies ranging from $88 \sim 95 \%$. An assessment by Kallman et al. (2011) in rural Guatemala indicated removal efficiencies ranging from $72 \sim 100 \%$, with a mean removal efficiency of $87 \%$.

The differences between removal efficiencies observed in laboratory settings and those observed in the field are the result of a variety of issues, including: cleaning regime, contamination of the filter element, and contamination of the reservoir/receptacle. Contamination is more likely to occur during field operation due to insufficient training of the end-user as well as contaminated/non-sterile environments. The shape and size $(7 \sim 8 \mathrm{~kg})$ of CWFs make it difficult to follow recommended cleaning regimes while avoiding contamination. The CWF may be being placed on non-sterile surfaces to aid in cleaning as well as being supported using hands on the bottom and/or side due to the weight, while performing filter maintenance, both of which contribute to contamination of the outside surfaces of the CWF.

The purpose of this research is to determine the impact of field conditions on CWF performance and identify possible improvements/modifications for future use. Field data are a more realistic representation of the effectiveness of CWFs for rural populations and therefore identification of issues impacting field operation enables improved design of CWFs in the future.

\section{Materials and Methods}

\subsection{Laboratory Study}

Laboratory studies were completed at the University of Guelph, Ontario, Canada. Two CWFs were analyzed and a non-pathogenic strain of E. coli was employed (ATCC 700891). Influent E. coli concentrations employed throughout all laboratory trials ranged from $10^{4}$ to $10^{5} \mathrm{CFU} / 100 \mathrm{~mL}$. All samples were plated in triplicate at a variety of dilutions and method blanks were utilized during the enumeration procedure. The CWFs were sourced from the same manufacturer as those employed in field trials. The source water utilized in laboratory trials was sterile deionized water.

\subsection{Field Study}

Field studies took place in Longhai City in the Fujian province of the People's Republic of China. Longhai is a county-level city within the prefecture city of Zhangzhou. Eight CWFs (sourced from the same manufacturer as those utilized in the laboratory study) were utilized in eight separate households of which three used one of several well water sources (see Figure S1 as a typical example), and five used spring water (see Figure S2, where water is collected in a concrete reservoir and subsequently piped to households via a simple dendritic distribution system). Source water was added 
to each CWF by the village residents, from their designated water source, at least once per day to prevent drying of the filter element and to aid in the establishment of a biofilm. CWFs were used for one month before sampling began. Samples were periodically collected over a two-month study period (January March 2016).

\subsection{E. coli Enumeration Procedure}

E. Coli were enumerated in accordance with EPA Method 1603: Escherichia coli in Water by Membrane Filtration in both laboratory and field studies.

\subsection{Microscopy Procedure}

A Keyence VHX-5000 digital microscope was employed for surface analysis of CWFs. Images were produced using depth-in configuration with automatic 3D image stitching. Automatic area measurements were taken to quantify the size and number of pores.

\subsection{Statistical Analysis}

A $t$-Test was employed for statistical comparison between data sets (McBean and Rovers, 1998). Statistical significance was established at $5 \%(\mathrm{p}<0.05)$.

The relationship between log-phase reduction and reduction percentage is characterized in Equation (1), where one log-phase reduction is equivalent to $90 \%$ removal, two logphase reduction is equivalent to $99 \%$ removal, etc.

$$
\log \text { Removal }=-\log (1-\text { Removal\%/100) }
$$

\section{Results and Discussion}

\subsection{Microscopic Analysis}

CWFs were analyzed for pore size and distribution (Table 1, Figure S3). Data indicate a pore fraction of $21.0 \sim 22.4 \%$, an average maximum pore diameter of $5.7 \sim 15.2 \mu \mathrm{m}$ and an average minimum pore diameter of $3.9 \sim 10.0 \mu \mathrm{m}$. Bacteria range in length from $1 \sim 50 \mu \mathrm{m}$. Therefore, the majority of bacteria are expected to be removed from the influent water by size exclusion.

\subsection{Laboratory Study}

E. coli removal efficiency data obtained from laboratory trials are depicted in Figure 2. Average removal efficiency of $E$. coli ranged from $97.7 \sim 99.9 \%$. There was insufficient evidence of a significant difference $(p>0.05)$ between the two CWFs tested indicating that the two CWFs were not significantly different in terms of $E$. coli removal efficiency. CWF 1 demonstrated larger variation in removal efficiency compared to CWF 2. This result is due to variations in manufacture, primarily the presence of micro-cracks and/or large pores. Micro-cracks and large pores typically dominate flow and achieve less removal.
Table 1. Pore Size Analysis of CWFs Utilizing Keyence VHX-5000 Digital Microscope

\begin{tabular}{lll}
\hline & CWF 1 & CWF 2 \\
\hline Average Pore Size (Max. Diameter, $\mu \mathrm{m}^{*}$ ) & 5.7 & 15.2 \\
& $(16.7)$ & $(11.1)$ \\
Average Pore Size (Min. Diameter, $\mu \mathrm{m}^{*}$ ) & $3.9(12)$ & 10.0 \\
& & $(8.1)$ \\
Largest Pore $(\mu \mathrm{m})$ & 113 & 63.8 \\
Pore Fraction & $21.0 \%$ & $22.4 \%$ \\
\hline
\end{tabular}

*Bracketed values indicate standard deviation.

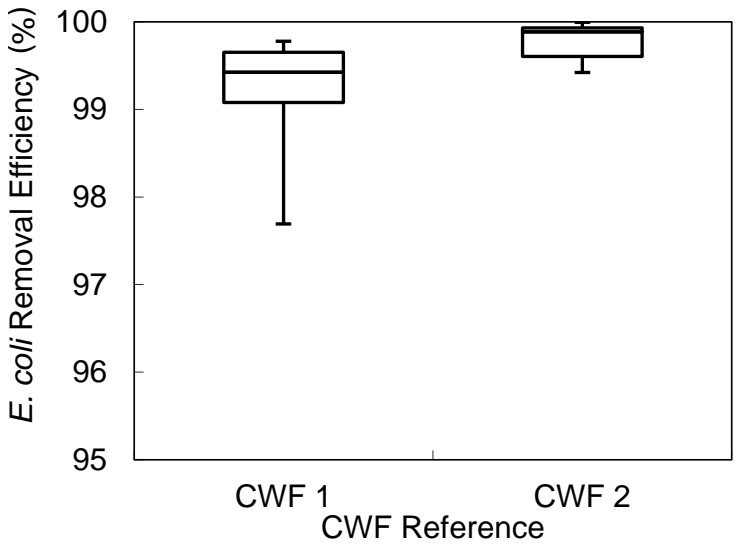

Figure 2. Removal efficiency of E. coli during laboratory studies at the University of Guelph, Canada utilizing sterile source water spiked with a non-pathogenic E. coli $(n=6)$. Note: Box represents $25^{\text {th }}$ and $75^{\text {th }}$ percentiles; lines extending vertically from the boxes (whiskers) represent maximum/minimum values.

\subsection{Field Study}

Data obtained from field studies in Longhai, China are shown in Figures 3 and 4. Influent water quality is summarized in Table 2. The removal efficiencies of $E$. coli during field studies were observed to have a broad range, from $75 \sim 100 \%$. There was no evidence of a significant difference $(p>0.05)$ in influent quality between water sourced from the wells and water sourced from the concrete reservoir. Influent concentrations ranged from 113 to $1900 \mathrm{CFU} / 100 \mathrm{~mL}$. There was no significant change in removal efficacy over time, indicating that CWFs/receptacles did not become increasingly contaminated as the trial progressed and that formation of a biofilm did not significantly improve E. coli removal over the period of monitoring. There was no evidence of a statistically significant difference $(p>0.05)$ in E. Coli removal efficiency between CWFs that used spring water and those that used well water as an influent source.

Figure 5 depicts the E. coli removal efficiency associated with individual CWFs studied during field trials. The magnitude of variation associated with each CWF indicates that the sources of variation reflected in Figures 2 and 3 are not solely due to differences between individual CWF removal efficiencies but also due to variations in removal efficiencies over time. The magnitude of variation observed is much greater than can be solely attributed to variations from manufacture. 


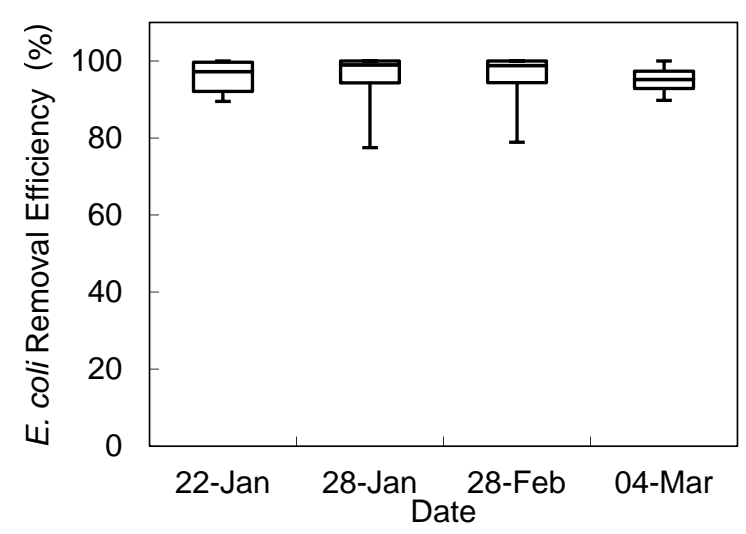

Figure 3. Removal efficiency of E. Coli during field studies in Longhai, China utilizing source water from springs $(\mathrm{n}=5)$. Note: Box represents $25^{\text {th }}$ and $75^{\text {th }}$ percentiles; lines extending vertically from the boxes (whiskers) represent maximum/minimum values.

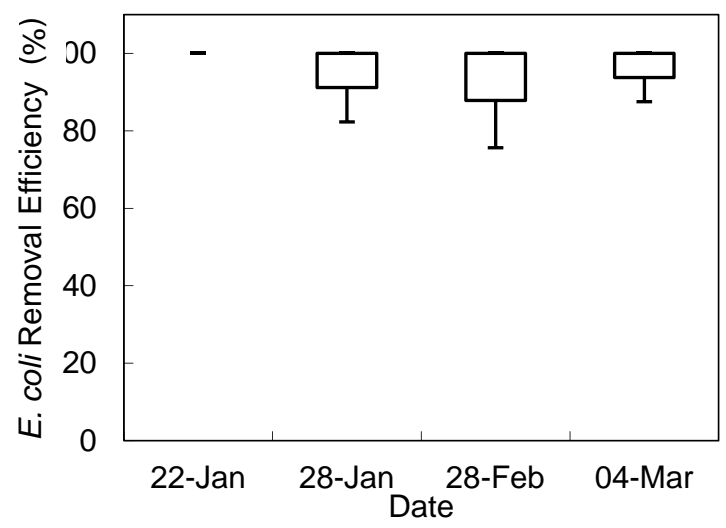

Figure 4. Removal efficiency of E. Coli during field studies in Longhai, China utilizing source water from wells $(\mathrm{n}=3)$. Note: On Jan. 22, 2016 only one sample was collected. Box represents $25^{\text {th }}$ and $75^{\text {th }}$ percentiles; lines extending vertically from the boxes (whiskers) represent maximum/minimum values.
Table 2. Influent Water Quality

\begin{tabular}{lll}
\hline & Spring $(\mathrm{n}=5)$ & Well $(\mathrm{n}=3)$ \\
\hline $\mathrm{COD}(\mathrm{mg} / \mathrm{L})^{*}$ & $2.94(0.61)$ & $2.43(0.15)$ \\
$\mathrm{TN}(\mathrm{mg} / \mathrm{L})^{*}$ & $11.36(1.76)$ & $7.83(0.65)$ \\
$\mathrm{NO}_{3}-\mathrm{N}(\mathrm{mg} / \mathrm{L})^{*}$ & $7.84(0.54)$ & $6.8(0.36)$ \\
\hline
\end{tabular}

* Bracketed values indicate standard deviation.

Changes in the E. coli removal efficiency of a single CWF, as depicted in Figures 2 and 3, include the effect of external contamination from either the filter element or the plastic receptacle, probably as a result of contamination by the enduser. It is unlikely that a CWF would exhibit the fairly high level of variation observed in these findings, unless occasional contamination of the filter element was occurring. As noted previously, removal efficiencies did not decline over time but changed irregularly from week to week (see Figure 5) indicating an irregular source of contamination.

\subsection{Comparative Analysis}

A comparison between field and laboratory studies indicates sufficient evidence of a statistically significant differrence in $E$. coli removal efficiency between field and laboratory studies $(p<0.05)$. Differences between field and laboratory studies include: influent concentrations (significantly higher source water concentrations in the laboratory studies), cleaning regime, and maintenance of sterile conditions arising from improper CWF cleaning during field studies.

Comparison between the study results presented herein and other field and laboratory studies (see Figure 6) strengthens the aforementioned trends as observed between field and laboratory trials. Field studies conducted by Kallman et al. (2011) and Malapane and Hackett (2012) depict similar E. coli removal efficiencies to the current field study in Longhai, China. Laboratory studies conducted by Lantagne (2001a), Fahlin (2003), Campbell (2005), and Duke et al. (2006) also show similar removal efficiencies to the current laboratory results, although a laboratory study reported by Van Halem et al. (2007) shows significantly higher removal of E. coli (evident

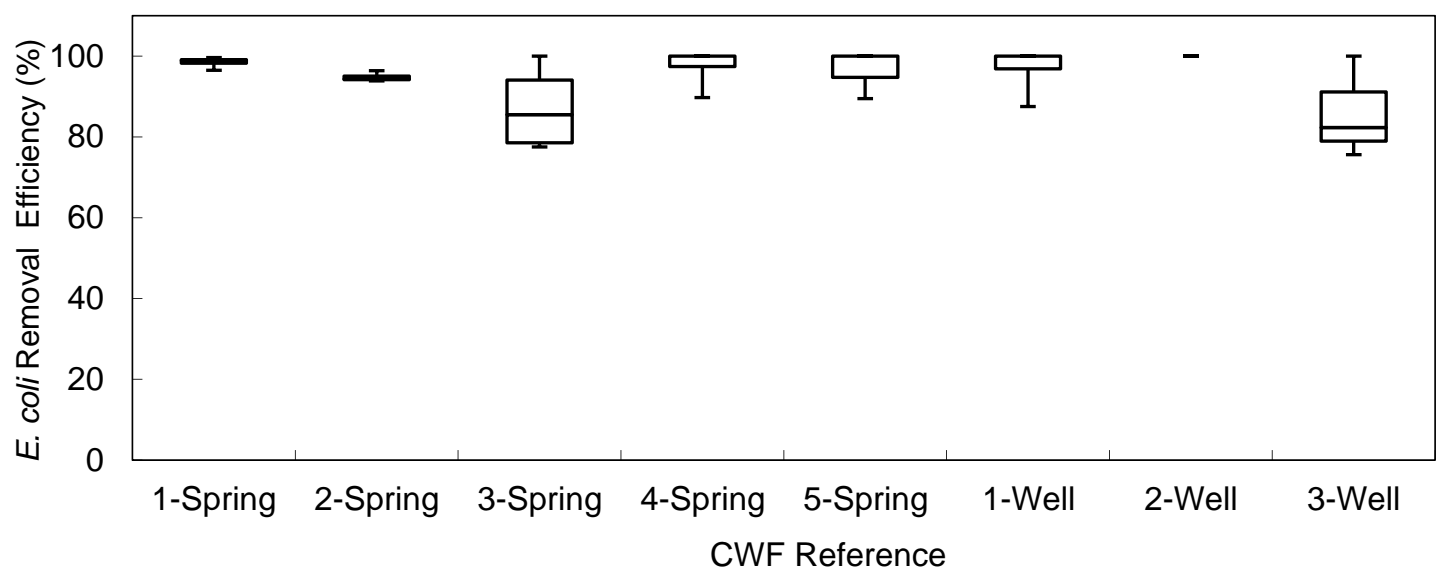

Figure 5. Removal efficiency of E. Coli during field studies in Longhai, China utilizing both well and spring source water. Note: Box represents 25th and 75th percentiles; lines extending vertically from the boxes (whiskers) represent maximum/ minimum values. 


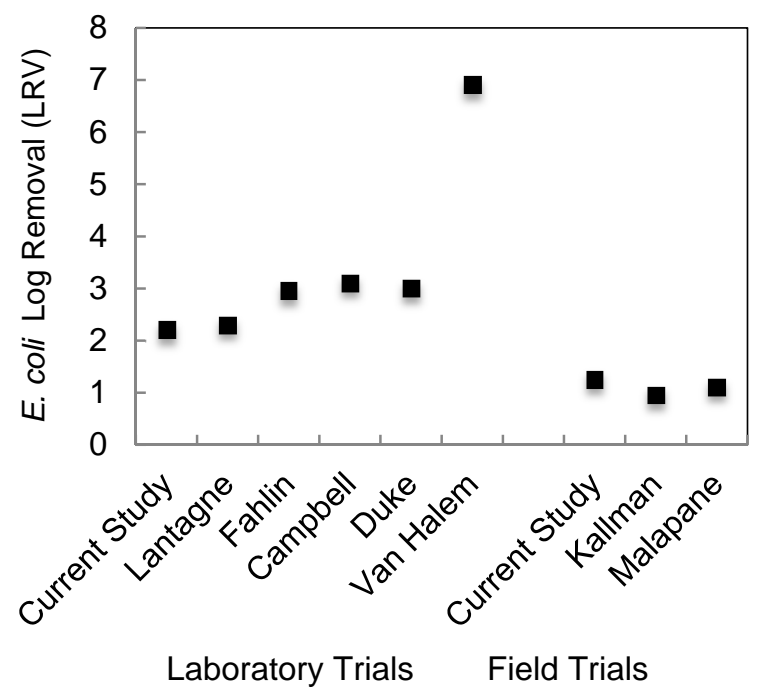

Figure 6. Removal efficiencies of E. coli: comparison between laboratory and field trials (Lantagne, 2001a; Fahlin, 2003; Campbell, 2005; Duke et al., 2006; Van Halem et al., 2007; Kallman et al., 2011; Malapane and Hackett, 2012).

by the plotted values in Figure 6). Average E. coli removal efficiencies in the lab and field were observed to be 99.5 and $94.7 \%$ respectively.

The differences in removal efficiency between field and laboratory conditions are attributed primarily to cleaning regime, influent concentration, and accidental contamination of the CWF and receptacle. Clearly, any contamination of the exterior surface of CWFs during cleaning in the field leads to contamination of the filtered water. Although the rural householders were advised to not do so, users were observed to be touching the external surface of the filter element during site visits. The CWFs utilized in this study were $8 \mathrm{~kg}$ and therefore difficult to clean without supporting the external surface. This support leads to contamination of the filter element. Utilizing a lighter ceramic filter would reduce the occurrence of external contamination, but the integrity of microorganism removal would be impacted and the potential for breakage would be increased. The fragile character related to a thinner ceramic filter is not worth the benefit of easier cleaning with the current $\mathrm{CWF}$ design.

In a laboratory setting, the external surfaces of the CWF are never contaminated and utmost care is taken to ensure a sterile receptacle. In the field, however, maintaining sterile conditions is difficult as referred to above, but issues of user activities during transfer of technology are very important.

\section{Conclusions}

The removal efficiency of E. coli by CWFs is significantly different in laboratory conditions versus field conditions. The CWFs employed in this study have a pore fraction of 21.0 $\sim 22.4 \%$ and an average maximum pore diameter of $5.7 \sim$ $15.2 \mu \mathrm{m}$. In the field, removal efficiency was observed to range from $75 \sim 100 \%$, whereas in laboratory studies removal efficiency was observed to range from $97.7 \sim 99.9 \%$. Average E. coli removal efficiencies in the lab and field were observed to be 99.5 and $94.7 \%$ respectively. The variations in removal efficiency are attributed to contamination of the filter element and receptacle when employed in the field indicating the importance of technology transfer to decrease contamination and improve performance during field use by end-users. These results also indicate that improvement of CWF design is warranted (lighter/less cumbersome filter element) to decrease the degree of contamination during field use.

Acknowledgement. Financial support for this research was provided by the United Nations Development Programme (UNDP).

Supporting Material. This paper contains supporting materials which are available in its online version.

\section{References}

Berg, P.A. (2015). The world's need for household water treatment. $J$. Am. Water Works Assoc., 107(10), 36-44. https://doi.org/10.5942/ jawwa.2015.107.0144

Campbell, E. (2005). Study on life span of ceramic filter colloidal silver pot shaped (CSP) model, Managua, Nicaragua. Potters for Peace. http://potterswithoutborders.com/wp-content/uploads/2011/ 06/filter-longevity-study.pdf

Duke, W.F., Nordin, R., and Mazumder, A. (2006). Comparative analysis of the filtron and biosand water filters. http://potterswithout borders.com/wpcontent/uploads/2011/06/comparative_analysis_of the fltron_and_biosand_water_filterseditms.pdf

Fahlin, C.J. (2003). Hydraulic properties investigation of the potters for peace colloidal silver impregnated, ceramic filter. http://potters withoutborders.com/wpcontent/uploads/2011/06/exec-summary-u niv-of-col-study.pdf

Farrow, C., McBean, E., and Salsali, H. (2014). Virus removal efficiency of ceramic water filters: Effects of bentonite turbidity. Water Sci. Technol. Water Supply, 14(2), 304-311. https://doi.org/ 10.2166/ws.2013.206

Kallman, E.N., Oyanedel-Craver, V.A., and Smith, J.A. (2011). Ceramic filters impregnated with silver nanoparticles for point-of-use water treatment in rural Guatemala. J. Environ. Eng., 137(6), 407415. https://doi.org/10.1061/ (ASCE)EE.1943-7870.0000330

Lantagne, D.S, (2001a). Investigation of the potters for peace colloiddal silver impregnated ceramic filter, Report 1: Intrinsic effectiveness. Alethia Environmental, Allston.

Lantagne, D.S. (2001b). Investigation of the potters for peace colloiddal silver impregnated ceramic filter, Report 2: Field investigations. Alethia Environmental, Allston.

Malapane, T.A., Hackett, C., Netshandama, and V., Simth, J. (2012). Ceramic water filter for point-of-use water treatment in Limpopo province. South Africa. Proceedings of the 2012 IEEE Systems and Information Engineering Design Symposium, University of Virginia, Charlottesville, VA, USA.

McBean, E.A. and Rovers, F.A. (1998). Statistical procedures for analysis of environmental monitoring data and risk assessment. Prentice-Hall Publishing Company, New Je-rsey.

Mellor, J., Abebe, L., Ehdaie, B., Dillingham, R., and Smith, J. (2014). Modelling the sustainability of a ceramic water filter intervention. Water Res., 49, 286-299. https://doi.org/10.1016/j.watres. 2013.11.035 
Murphy, H., Sampson, M., McBean, E., and Farabakhsh. (2010a). Influence of household practices on the performance of clay pot water filters in rural Cambodia. Desalination, 252, 145-152. https:// doi.org/10.1016/j.desal.2008.05.102

Murphy, H., McBean, E., and Farahbakhsh. (2010b). Microbial and chemical assessment of ceramic and biosand water filters in rural Cambodia. Water Sci. Technol. Water Supply, 10, 286-295. https:// doi.org/10.2166/ws.2010.221

Murphy, H., McBean, E., and Farahbakhsh, (2010c). A critical evaluation of two point-of-use water treatment technologies: Can they provide water that meets WHO drinking water guidelines? $J$. Water Health, 8, 611-630. https://doi.org/10.2166/wh.2010.156

Perez-Vidal, A., Diaz-Gomez, J., Castellanos-Rozo, J., and UsaquenPerilla, O.G. (2016). Long-term evaluation of the performance of four point-of-use water filters. Water Res., 98, 176-182. https://doi. $\operatorname{org} / 10.1016 /$ j.watres.2016.04.016

Rayner, J., Zhang, H., Schubert, J., Lennon, P., Lantange, D., and Oyanedel-Craver, V. (2013). Laboratory investigation into the effect of silver application on the bacterial removal efficiency of filter material for use on locally produced ceramic water filters for household drinking water treatment. Sustainable. Chem. Eng., 1, 737-745. https://doi.org/10.1021/sc400068p

Tchobanoglous, G., Burton, F., Stensel, M., and Metcalf \& Eddy Inc. (2003). Wastewater Engineering: Treatment and Reuse, McGrawHill Book Company, New York.

Thomas, K., McBean, E., Schantz, A., and Murphy, H. (2015). Comparing the microbial risks associated with household drinking water supplies used in peri-urban communities of Phnom Penh, Cambodia. J. Water Health, 13(1), 243-258. https://doi.org/10. 2166/wh.2014.214

van Halem, D. (2006). Ceramic silver impregnated pot filters for household drinking water treatment in developing countries, Master's Thesis, Faculty of Civil Engineering, Delft University of technology, Netherlands.

van Halem, D., Heijman, S.G.J., Soppe, A.I.A., van Dijk, J.C., and Amy, G.L. (2007). Ceramic silver-impregnated pot filters for household drinking water treatment in developing countries: material characterization and performance study. Water Sci. Technol. Water Supply, 7 (5-6), 9-17. https://doi.org/10.2166/ws.2007.142

Oyanedel-Craver, V. and Smith, J. (2008). Sustainable colloidalsilver impregnated ceramic filter for point-of-use water treatment. Environ. Sci. Technol., 42, 927-933. https://doi.org/10.1021/es071 $268 \mathrm{u}$

WHO/UNICEF. (2105). Lack of sanitation for 2.4 billion people is undermining health improvements. Final MDG progress report on water and sanitation released. Geneva/New York, USA.

WHO (2013). Diarrhoeal disease Fact Sheet. http://www.who.int/ mediacentre/factsheets/fs330/en/

WHO (2017). Water, Sanitation \& Hygiene, http://www.unwater. org/water-facts/water-sanitation-and-hygiene/

World Health Organization and UNICEF Joint Monitoring Programme (JMP) (2015). Progress on drinking water and sanitation, 2015 Update and MDG assessment.

Wright, J., Gundry, S., and Conroy, R. (2004). Household drinking water in developing countries: a systematic review of microbiological contamination between source and point-of-use. Trop. Med. Int. Health, 9, 106-117. https://doi.org/10.1046/j.1365-3156.2003. 01160.x

Yakub, I. and Soboyejo, W.O. (2012). Adhesion of E. coli to silveror copper-coated porous ceramic surfaces. Journal of Appl. Phys., 111(12), 124324. https://doi.org/10.1063/1.4722326 